\title{
Systemic treatment of breast cancer with leptomeningeal metastases using bevacizumab, etoposide and cisplatin (BEEP regimen) significantly improves overall survival
}

\author{
Tom Wei-Wu Chen ${ }^{1,2,3} \cdot$ I-Shiow Jan ${ }^{4}$ Dwang-Ying Chang ${ }^{1,2} \cdot$ Ching-Hung Lin ${ }^{1,2} \cdot$ I-Chun Chen ${ }^{1,2,3} \cdot$ Ho-Min Chen ${ }^{5}$. \\ Ann-Lii Cheng ${ }^{1,2,3} \cdot$ Yen-Shen Lu ${ }^{1,2}$ (D)
}

Received: 10 March 2020 / Accepted: 18 April 2020 / Published online: 29 April 2020

(c) The Author(s) 2020

\begin{abstract}
Introduction Metastatic breast cancer (MBC) with leptomeningeal metastases (LM) has dismal survival. We aim to determine if modern systemic therapy, especially the bevacizumab, cisplatin, and etoposide (BEEP) regimen, is beneficial to MBC LM patients.

Methods We excerpted data from a prospectively collected cytopathology database for MBC patients who were diagnosed with LM by positive cerebrospinal fluid cytology. The primary outcome was OS from cytologically confirmed LM until death. Univariate and multivariate analyses were performed to elucidate prognostic factors.

Results We identified 34 patients with cytologically confirmed LM. Treatments after LM diagnosis included: intrathecal methotrexate $(82.4 \%)$, systemic chemotherapy $(68 \%$; BEEP $n=19$, others $n=4)$, and whole brain radiotherapy $(n=5$, 14.7\%). Three of seven HER2-positive patients (43\%) also received intrathecal trastuzumab. OS was improved in 2014-2016 compared with 2011-2013 (13.57 vs 3.20 months, $p=0.004$ ), when 12/17 (71\%) versus 7/17 (41\%) patients received BEEP, respectively. In the multivariate model including all treatments, BEEP (HR 0.24, p =0.003) and intrathecal trastuzumab (HR $0.22, p=0.035$ ), but not intrathecal methotrexate (HR 0.86, $\mathrm{p}=0.78$ ), remained significant prognostic factors.

Conclusions MBC with LM is treatable—systemic BEEP are efficacious and may improve survival.
\end{abstract}

Keywords Bevacizumab · Breast cancer $\cdot$ Chemotherapy $\cdot$ Intrathecal therapy $\cdot$ Leptomeningeal metastasis $\cdot$ Trastuzumab

\section{Introduction}

Leptomeningeal metastasis (LM) is common in lung, breast, and renal cell cancers and melanomas, and is one of the most devastating metastatic disease scenarios [1]. The incidence of LM in metastatic breast cancer ranges widely, from 5 to $40 \%$, and the prognosis is very poor, with median overall survival (OS) of around 3-4 months from diagnosis [2, 3]. Furthermore, there is evidence of increasing incidence rates of central nervous system (CNS) metastases, including brain parenchyma and possibly leptomeninges, in metastatic breast cancer [4, 5]. Thus, patients with breast cancer LM desperately need new treatments or drug regimens that can improve their prognosis.

Although many potential treatments for LM have been evaluated, results hitherto have been unsatisfactory. Intrathecal chemotherapy, which has the advantage of not needing to penetrate the blood-brain-barrier to reach the cerebrospinal fluid (CSF), has been the favored treatment, but its efficacy 
remains uncertain [6]; despite the advantages of intrathecal chemotherapy, multiple studies suggested that its efficacy is modest at most [1, 6-8]. Systematic reviews have even suggested that intrathecal methotrexate is associated with increased toxicity, without improving outcomes $[6,9]$. Another promising intrathecal treatment for HER2-positive breast cancer with LM is trastuzumab; case reports have shown that intrathecal trastuzumab is a feasible treatment with limited toxicity [10], but more data are needed to determine its actual efficacy.

Although retrospective studies suggest that systemic treatment may improve the survival of breast cancer with LM $[9,11]$, many prospective trials of systemic treatments, such as temozolomide, have not demonstrated convincing clinical efficacy [12]. We recently devised a combination of the anti-vascular endothelial growth factor monoclonal antibody bevacizumab, plus etoposide and cisplatin (BEEP regimen), which has shown significant activity in patients with breast cancer and brain metastases that progressed after whole brain radiotherapy (WBRT) [13]. We reported promising results of patients with breast cancer LM who responded to the BEEP regimen, supporting the rationale for using BEEP to treat breast cancer patients with CNS metastases $[14,15]$.

The National Taiwan University Hospital (NTUH) criterion for definitive diagnosis of LM, is positive CSF cytology; this policy has dual benefits: first, it excludes patients with false-positive diagnoses based solely on CNS imaging; second, CSF cytology results can be used to accrue an unbiased dataset of patients with LM in real-world practice. The aim of this study was to assess the effect of systemic BEEP on OS of breast cancer patients with cytologically confirmed LM.

\section{Methods}

We used the NTUH cytopathology database to identify patients from 2011 to 2016 with confirmed breast cancer and CSF cytology results positive for LM. Clinicopathologic data and treatment modalities were excerpted from electronic medical records. The NTUH Research Ethics Committee approved the study under a blanket protocol (201003025R) for analysis of medical data from patients with stage IV breast cancer. Informed consent from the patients was waived for retrospective medical record review studies per the protocol of the NTUH Research Ethics Committee. Estrogen receptor (ER) and human epidermal growth factor receptor-2 (HER2) status were determined based on primary breast tumor samples; patients with $\geq 1 \%$ of nuclear immunohistochemistry staining were considered ER positive and HER2 status was defined according to current American Society of Clinical Oncology criteria [16].
The first date of confirmed CSF cytology for malignant cells was considered the index date for treatment and survival. The first intrathecal and systemic treatments received after LM was confirmed were noted. WBRT was defined as having received WBRT within $\leq 30$ days of the index date. The BEEP regimen entailed a 21-day cycle of bevacizumab $(15 \mathrm{mg} / \mathrm{kg}$ ) on day 1 , followed by cisplatin and etoposide (both $70 \mathrm{mg} / \mathrm{m}^{2}$ ) on day 2 , then etoposide $\left(70 \mathrm{mg} / \mathrm{m}^{2}\right)$ only on days 3 and 4 [13].

The primary endpoint was OS, defined as the period elapsed from the index date until death or last followup, in August 2018. The progression of LM was defined by the deteriorating of neurological symptoms. The time to response was calculated from the index date to the first negative cytology report date; patients with two consecutive negative CSF cytology assessments were considered responsive to LM treatment.

\section{Statistical analysis}

All statistical analyses were performed using SAS, version 9.4 (SAS Institute Inc., Cary, NC, USA). Kaplan-Meier survival curves with $95 \%$ pointwise confidence limits and log-rank tests were used to elucidate associations between prognostic factors and OS. Univariate and multivariate Cox proportional hazard models were used to estimate hazard ratios (HRs) and 95\% confidence intervals (CIs). To determine which treatments may be most beneficial for patients with LM, all that were significantly associated with OS in univariate analyses, were tested in the multivariate model. A p-value of $<0.05$ was considered significant and no multiple comparison corrections were performed.

\section{Results}

\section{Patient characteristics}

From 2011 to 2016, the NTUH cytopathology database recorded 34 cases of breast cancer with cytologically confirmed LM; Table 1 summarizes the patients' clinicopathologic characteristics. All were females, with median age of 57 (30-80) years at LM diagnosis, and $>80 \%$ were initially diagnosed with stage III or IV breast cancer. The median interval from first breast cancer diagnosis to LM was 34.2 months (0.7-149.8) and from metastatic disease diagnosis to confirmed LM was $~ 16.7$ months (0-98.9).

Primary breast tumors were predominantly ER-positive (21/34), HER2-negative (27/34), with 10/34 triple negative. Eight patients (23.5\%) had lobular histology. Despite LM, 12/34 patients did not have synchronous parenchymal brain metastases; common metastatic sites besides CNS included bone, liver, lung, and soft tissue/lymph node. 
Table 1 Characteristics of 34 patients with leptomeningeal metastases from breast cancer

\begin{tabular}{|c|c|}
\hline Data show median [range] or number (\%) & \\
\hline Year of leptomeningeal metastases diagnosis & \\
\hline $2011-2013$ & $17(50.0)$ \\
\hline 2014-2016 & $17(50.0)$ \\
\hline Age at leptomeningeal metastasis diagnosis & $57.0[30.0,80.0]$ \\
\hline Age at first breast cancer diagnosis & $53.0[26.0,77.0]$ \\
\hline Breast cancer stage at first diagnosis & \\
\hline II & $6(17.6)$ \\
\hline III & $15(44.1)$ \\
\hline IV & $13(38.2)$ \\
\hline Interval breast cancer diagnosis to leptomeningeal metastases (months) & $34.2[0.7,149.8]$ \\
\hline Interval from stage IV diagnosis to leptomeningeal metastases (months) & $16.7[0.0,98.9]$ \\
\hline Histology & \\
\hline Carcinoma & $4(11.8)$ \\
\hline Ductal & $22(64.7)$ \\
\hline Lobular & $8(23.5)$ \\
\hline Subtype & \\
\hline $\mathrm{ER}+$ & $21(61.8)$ \\
\hline HER $2+$ & $7(20.6)$ \\
\hline TNBC & $10(29.4)$ \\
\hline Brain metastasis & \\
\hline Synchronous & $12(35.3)$ \\
\hline Metachronous & $10(29.4)$ \\
\hline Not present & $12(35.3)$ \\
\hline Extra-CNS metastasis & \\
\hline Any & $26(76.5)$ \\
\hline Bone & $20(58.8)$ \\
\hline Liver & $12(35.3)$ \\
\hline Lung & $8(23.5)$ \\
\hline Soft tissue/lymph nodes & $2(5.9)$ \\
\hline Stereotactic radiosurgery before leptomeningeal metastases diagnosis & $7(20.6)$ \\
\hline Interval from stereotactic radiosurgery to leptomeningeal metastases (months) & $3.2[0.86,18.6]$ \\
\hline Whole brain radiotherapy before leptomeningeal metastases diagnosis & $8(23.5)$ \\
\hline Interval from whole brain radiotherapy to leptomeningeal metastases (months) & $5.5[2.58,24.56]$ \\
\hline Treatment after leptomeningeal metastases diagnosis & \\
\hline Intrathecal methotrexate & $28(82.4)$ \\
\hline Systemic therapy & $23(67.6)$ \\
\hline BEEP regimen & $19(55.9)$ \\
\hline Other regimens $^{\mathrm{a}}$ & $4(11.7)$ \\
\hline Anti-HER 2 therapy ( $\%$ of HER 2 + patients) & $3(42.9)$ \\
\hline Whole brain radiation therapy ( \pm 30 days) & $5(14.7)$ \\
\hline
\end{tabular}

$E R$ estrogen receptor, $H E R 2$ human epidermal growth factor receptor-2, TNBC triple negative breast cancer, $C N S$ central nervous system, $B E E P$ bevacizumab, etoposide, and cisplatin

${ }^{\mathrm{a}}$ Capecitabine (1), etoposide \& cisplatin (1), paclitaxel \& gemcitabine (1), bevacizumab, docetaxel \& cisplatin (1)
Non-surgical treatments of metastatic brain tumors before LM diagnosis included stereotactic radiosurgery (SBRT) and WBRT. The median interval from previous SBRT and WBRT to LM diagnosis was 3.2 and 5.5 months, respectively.

\section{Treatment for LM}

Patients with LM generally received concomitant multimodal treatments after the index diagnosis; most received at least one dose of intrathecal methotrexate and systemic 
chemotherapy. The BEEP regimen was the first-line systemic treatment for $19 / 23$ patients, and only $2 / 23$ who received systemic treatment did not receive intrathecal methotrexate. Three of seven patients with HER2-positive breast cancer with LM had also received concomitant intrathecal trastuzumab during the treatment course, but none before the LM index date.

\section{Survival analysis}

The median OS of all 34 patients was 5.2 months (95\% CI 2.2-9.7); 31 had died when survival data were collected (Fig. 1a). Survival rates at 1 and 2 years were $29 \%$ and $10 \%$, respectively. In univariate analyses (Table 2), intrathecal methotrexate was significantly associated with better OS. Although improved survival with systemic treatment was not statistically significant $(p=0.070)$, breast cancer patients with LM who received BEEP had significantly prolonged survival compared to those treated with other regimens; the median OS of patients who received BEEP regimens was 9.7 months compared with 1.4 months for those on nonBEEP regimens $(p=0.002)$. Another significant prognostic factor was previous stereotactic radiosurgery for brain metastases. ER or HER2 status were not significantly associated with OS. Breast cancer subtype and brain metastases were not significantly different between BEEP and nonBEEP-treated patients (Supplementary Table 1).

We saw a trend towards increased use of systemic BEEP for breast cancer patients with LM during 2014-2016 compared with 2011-2013 ( $\mathrm{p}=0.08$, Chi-Square test). In parallel, OS was significantly longer in 2014-2016 than in 2011-2013 (13.6 vs 3.2 months, $p=0.0036$ ) (Fig. 1b).

For the two patients of three who received both intrathecal trastuzumab and intrathecal methotrexate, who also received BEEP, the median OS was 17.0 months (95\% CI 15.4-24.8) (Fig. 1c).

\section{Treatment effects}

In the adjusted Cox proportional hazard model (Table 3), BEEP remained a significant prognostic factor for OS. The impact of intrathecal MTX became non-significant but intrathecal trastuzumab had significant prognostic impact for HER2-positive patients. The survival curves of BEEP (all received intrathecal methotrexate), intrathecal methotrexate without BEEP, and no treatment were shown in Fig. 1c.

Table 4 compares the treatment response rates and outcomes of patients with different breast cancer subtypes and who received different treatment modalities. Patients who had a CSF response had significantly better OS than those who did not (HR $0.25,95 \%$ CI $0.11-0.55, \mathrm{p}<0.001$ ).
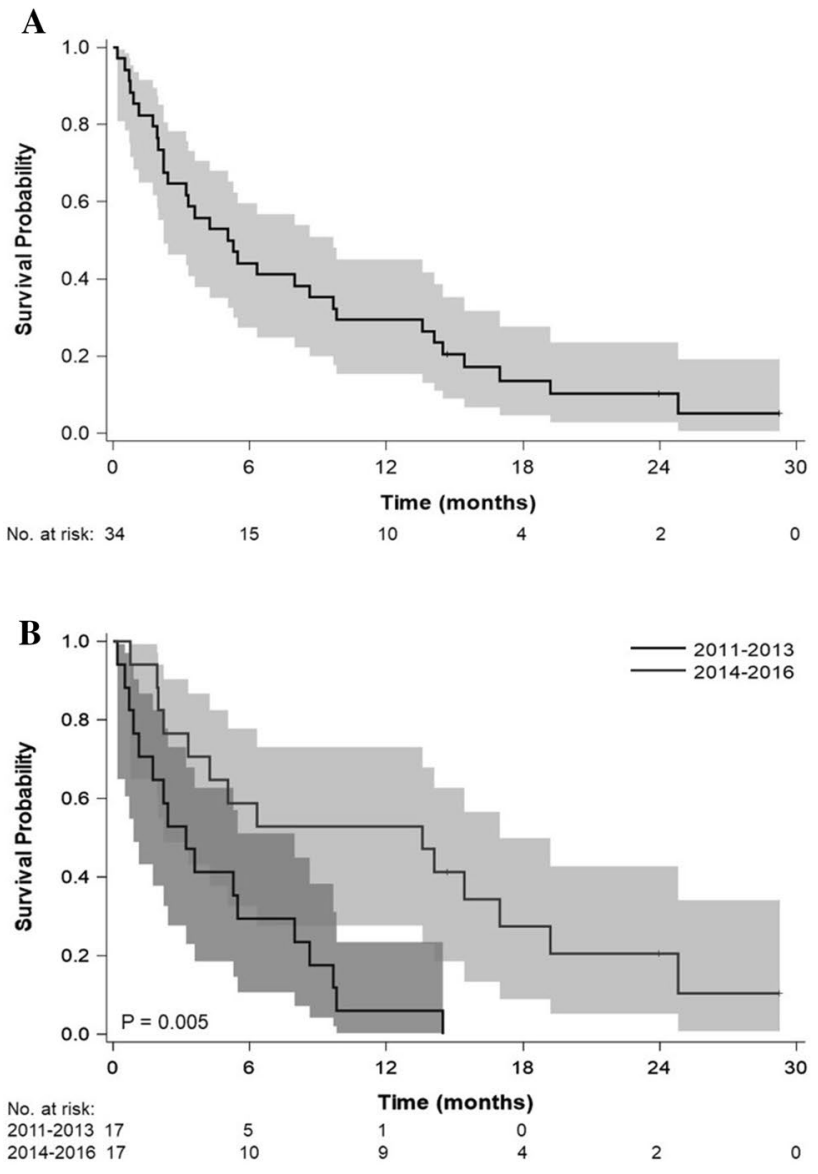

C

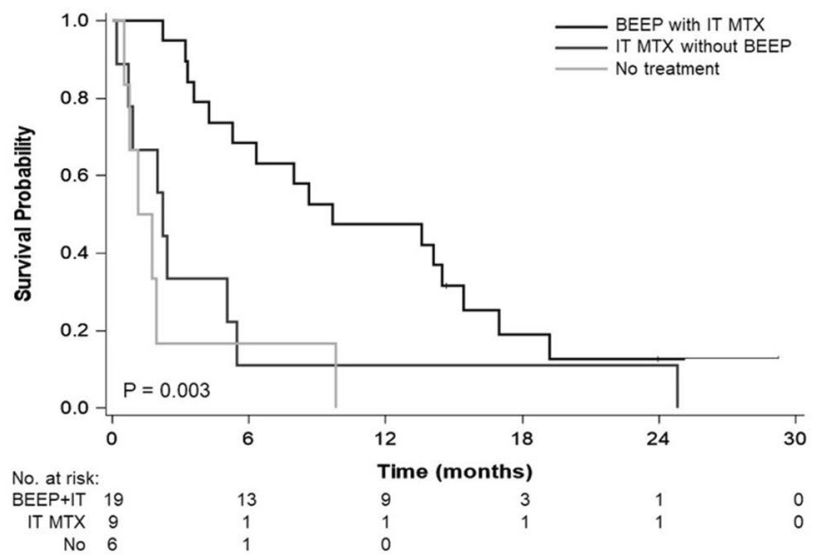

Fig. 1 a Kaplan-Meier survival curves with 95\% confidence intervals for the entire cohort $(n=34)$. b Kaplan-Meier survival curves of patients treated from 2011-2013 vs 2014-2016. c Kaplan-Meier survival curves of patients who received different treatments. BEEP bevacizumab, etoposide, cisplatin, IT MTX intrathecal methotrexate

\section{Discussion}

To the best of our knowledge, this is one of the largest reported cohorts to have received the systemic BEEP 
Table 2 Univariate hazard ratios for overall survival of 34 patients with leptomeningeal metastasis

\begin{tabular}{lll}
\hline & Hazard ratio $(95 \%$ CI $)$ & p-value \\
\hline Year & & \\
$2011-2013$ & Ref. & 0.005 \\
$2014-2016$ & $0.31(0.14,0.71)$ & \\
Age at leptomeningeal metastasis diagnosis & & 0.166 \\
$\leq 55$ years & Ref. & \\
$>$ 55 years & $1.66(0.81,3.42)$ & 0.006 \\
Intrathecal methotrexate vs non-intrathecal methotrexate & $0.27(0.10,0.69)$ & 0.070 \\
Systemic treatment & $0.50(0.24,1.06)$ & 0.002 \\
BEEP vs non-BEEP & $0.32(0.15,0.66)$ & 0.143 \\
Anti-HER2 therapy (intrathecal) & $0.40(0.12,1.36)$ & 0.495 \\
With vs without whole brain radiotherapy & $1.41(0.53,3.74)$ & 0.033 \\
With vs without prior stereotactic radiation surgery & $0.34(0.13,0.92)$ & 0.101 \\
Histology & & \\
Lobular carcinoma & Ref. & \\
Other carcinoma & $2.17(0.86,5.44)$ & 0.051 \\
Brain parenchyma metastasis & & \\
None & Ref. & \\
Metachronous & $0.41(0.16,1.03)$ & \\
Synchronous & $1.26(0.54,2.92)$ & \\
Breast cancer subtype & Ref. & \\
ER+/HER2- & $0.80(0.32,2.01)$ & \\
HER2+ & $0.91(0.39,2.10)$ & \\
Triple negative & & \\
\hline
\end{tabular}

$B E E P$ bevacizumab, etoposide, and cisplatin regimen, $E R$ estrogen receptor, HER2 human epidermal growth factor receptor-2
Table 3 Adjusted hazard ratios of treatments for leptomeningeal metastasis in 34 patients

\begin{tabular}{llc}
\hline & $\begin{array}{l}\text { Adjusted hazard ratio }(95 \% \\
\mathrm{CI})\end{array}$ & $\mathrm{p}$-value \\
\hline $\begin{array}{l}\text { Intrathecal methotrexate vs } \\
\text { non-intrathecal methotrexate }\end{array}$ & $0.86(0.28,2.64)$ & 0.787 \\
$\begin{array}{l}\text { BEEP vs non-BEEP } \\
\begin{array}{l}\text { Intrathecal trastuzumab vs no } \\
\text { intrathecal trastuzumab }\end{array}\end{array}$ & $0.24(0.09,0.62)$ & 0.003 \\
\hline
\end{tabular}

$B E E P$ bevacizumab, etoposide, and cisplatin regimen, HER2 human epidermal growth factor recptor-2

regimen after diagnosis of LM. We have affirmed that breast cancer with LM responds to treatment and that using systemic BEEP is associated with prolonged OS, potentially widening the efficacy of BEEP to include this indication. Furthermore, we also observed various patients who had a dramatic neurological recovery after systemic BEEP treatment. Although the details of quality-of-life was not recorded in the medical chart, the impressive changes in functional status implied that systemic treatments should still be considered and discussed for LM patients with deteriorating performance status.
Vascular endothelial growth factor has been implicated in LM progression [17], and higher levels in CSF are associated with worse prognosis of melanomas and breast cancer with LM [18]. Antiangiogenic therapy potentiates vascular normalization that may facilitate the transit of chemotherapeutic agents [19]; this effect has been shown to improve the perfusion and delivery of antiangiogenic drugs to treat glioblastoma [20]. In our previous study, more substantial changes in $\mathrm{K}^{\text {trans }}$, a biomarker for vascular permeation as measured by dynamic contrast enhanced magnetic resonance imaging, after $24 \mathrm{~h}$ of bevacizumab infusion was associated with longer control of brain parenchymal metastatic tumors in MBC [21, 22]. Although our previous findings were limited to MBC patients with brain parenchyma metastases, the fact that three out of four systemic chemotherapies without concomitant bevacizumab were not associated with an improved outcome in LM provides further indirect evidence that the efficacy of the BEEP regimen in LM may also related to vascular normalization.

Despite the potential risk of leukoencephalopathy in patients treated with intrathecal methotrexate, and we did not identify any risk factors associated leukoencephalopathy; our study also showed that intrathecal methotrexate may not be as important as systemic chemotherapy for treating LM. 
Table 4 Responses of 34 patients to treatment for leptomeningeal metastasis

\begin{tabular}{|c|c|c|c|}
\hline & \multicolumn{2}{|l|}{ CSF response } & \multirow[t]{2}{*}{ p-value ${ }^{a}$} \\
\hline & Number (\%) & $\mathrm{OR} *(95 \% \mathrm{CI})$ & \\
\hline All patients & $19 / 34(58 \%)$ & - & \\
\hline ER+ & $13 / 21(61.9 \%)$ & $1.90(0.47,7.70)$ & 0.484 \\
\hline HER 2+ & $6 / 7(85.7 \%)$ & $6.46(0.68,61.16)$ & 0.104 \\
\hline TNBC & $3 / 10(30.0 \%)$ & $0.21(0.04,1.06)$ & 0.068 \\
\hline Median time to CSF response (days) & $28[8,138]$ & & \\
\hline $\begin{array}{l}\text { CSF response to intravenous BEEP plus intrathecal methotrexate vs to } \\
\text { monomodal or no treatment }\end{array}$ & & $\mathrm{OR}=3.25(0.79,13.30)$ & 0.100 \\
\hline Overall survival of patients with vs without a CSF response & & $\mathrm{HR}=0.25(0.11,0.55)$ & $<0.001$ \\
\hline
\end{tabular}

$C S F$ cerebrospinal fluid, $E R$ estrogen receptor, $H E R 2$ human epidermal growth factor receptor-2, TNBC triple-negative breast cancer, $B E E P$ bevacizumab, etoposide, and cisplatin regimen, $O R$ odds ratio, $H R$ hazard ratio

${ }^{a}$ For each subtype, a $2 \times 2$ table of all patients were constructed, fisher exact test was performed, and OR was calculated

Although intrathecal methotrexate may alleviate neurological symptoms caused by a large tumor cell load, other studies suggest that intrathecal cytotoxic treatment may not be as efficacious as previously supposed $[6,8,9,11]$. A systemic review concluded that intrathecal cytotoxic agents have no real benefit and increase the risk of adverse effects [6]. However, patients in most retrospective studies, including ours, received intrathecal cytotoxic agents and systemic treatment concurrently, so we cannot rule out a synergistic effect of intrathecal and systemic treatment. Prospective studies with BEEP alone or with intrathecal methotrexate strategies are necessary to clarify the role of intrathecal cytotoxic agents in treating LM.

Conversely, intrathecal trastuzumab was associated with significantly improved survival in three of our seven HER2positive patients; notably, none of them received intravenous trastuzumab, supporting attribution of the benefit of trastuzumab to intrathecal delivery. Several case reports have found intrathecal trastuzumab efficacious for patients with HER2-positive breast cancer with LM refractory to intravenous trastuzumab-based regimens [10]. A recent phase I study of intrathecal trastuzumab for LM confirmed its safety, with a recommended phase II dose of $150 \mathrm{mg} /$ week [23]; phase II clinical trials are ongoing and we eagerly await the results.

A higher proportion of patients in our study than in the general primary breast cancer population had lobular carcinoma $(23.5 \%$ vs $10.0 \%)$, similar as reported in other LM studies of breast cancer [3]. Interestingly, one-third developed the first metastatic site in the leptomeninges without brain parenchymal metastases; despite LM, another third had synchronous brain metastasis and $29.4 \%$ had metachronous brain metastasis prior to LM diagnosis. Furthermore, different patterns of CNS involvement associated with LM had different prognosis, suggesting that the underlying pathogenesis of metastatic breast cancer and LM may not entirely overlap; for example, patients with LM not involving the parenchyma had worse survival than those with brain metastases followed by metachronous LM. Notably, patients who had stereotactic radiosurgery for brain metastasis had survived better after LM was diagnosed. Although the use of stereotactic radiosurgery may be governed by the numbers of metastatic tumors, other possible immunogenic or abscopal effects of stereotactic radiosurgery may also explain improved survival with prior treatment [24]. Boire et al. recently demonstrated that activation of the immune compliment system is associated with LM but not brain metastasis, in humans and mouse models [25], suggesting that we may need to rethink the treatment of LM patients.

Our study had limitations, foremost the caveat of selection bias inherent in retrospective studies. However, we endeavored to minimize this possibility by objectively including all patients with LM in the NTUH cytopathology database. As it is our policy to do CSF testing for every LM case suspected for clinical or radiological reasons, every cytological CSF assessment would leave a record. Efficacy of BEEP regimen against LM in only 34 patients may also be questioned; however, objective endpoints such as OS and response by consecutive CSF cytology results substantiate our results. Moreover, a multivariate model to differentiate the contribution of each treatment modality also affirmed superior activity of the BEEP regimen. On the other hand, all patients who received the BEEP regimen also received intrathecal methotrexate, so research is warranted to investigate whether the effect of BEEP is synergistic with intrathecal treatment. Secondly, although intrathecal trastuzumab was associated with better OS, none of the patients with HER2-positive breast cancer with LM received intravenous trastuzumab, and continued systemic anti-HER2 treatment after CNS metastases may be associated with improved survival [2]. However, as Taiwan National Health Insurance does not reimburse trastuzumab after progression on 
first-line treatment, trastuzumab would be expensive to buy out-of-pocket. Our results suggest that intrathecal trastuzumab may an alternative for patients with HER2-positive breast cancer with LM who cannot afford intravenous trastuzumab. Lastly, the results of OS may be subject to lead-time bias if the criteria to initiate diagnostic or treatment procedures are different from patient-to-patient. However, all the patients in this study were treated by the same breast medical oncologists through the time periods as such that the criteria for LM diagnosis and treatment would be similar across the patients, limiting the chance of lead-time bias.

\section{Conclusions}

Using a non-biased study design to evaluate systemic therapy for breast cancer with LM in a real-world clinical setting, we have shown that LM is a treatable, with a median OS of 9.63 months for patients receiving systemic BEEP treatment. Intrathecal methotrexate may not have additional benefit with the BEEP regimen. Nonetheless, intrathecal trastuzumab is associated with significantly improved OS in patients with HER2-positive breast cancer with LM. A clearer understanding of the role of systemic regimens, especially BEEP, in LM is needed to improve the management and prognosis of breast cancer with LM.

Acknowledgements This study was partially supported by YongLin Healthcare Foundation. Dr. David Neil (PhD), of Full Universe Integrated Marketing, Taiwan, provided professional editorial services and his colleague Pei Chi Kuo assisted with manuscript preparation project management; their contributions were supported by funding from National Taiwan University Hospital.

Author contribution Conception and design were contributed by TWC, ISJ, YSL; acquisition, analysis and interpretation of data, manuscript writing and final manuscript approval were contributed by all authors.

Funding This research did not receive any specific grant from funding agencies in the public, commercial, or not-for-profit sectors.

Data availability The datasets generated and analyzed during the current study are not publicly available due no permission from the authorized institution, but are available from the corresponding author on reasonable request.

\section{Compliance with ethical standards}

Conflict of interest TWC reports personal fees from Roche for honorarium. YSL reports clinical trial study fee from Novartis, Roche, Merck Sharp \& Dohme, Pfizer, and GlaxoSmithKline; personal fees from Novartis, Pfizer, Boehringer Ingelheim, and Eisai for consultant fee and honorarium. ALC reports clinical trial study fee and honorarium from Roche. All other authors have no conflict of interest.

Ethical approval The NTUH Research Ethics Committee approved the study under a blanket protocol (201003025R) for analysis of medical data from patients with stage IV breast cancer. Informed consent from the patients was waived for retrospective medical record review studies per the protocol of the NTUH Research Ethics Committee.

Open Access This article is licensed under a Creative Commons Attribution 4.0 International License, which permits use, sharing, adaptation, distribution and reproduction in any medium or format, as long as you give appropriate credit to the original author(s) and the source, provide a link to the Creative Commons licence, and indicate if changes were made. The images or other third party material in this article are included in the article's Creative Commons licence, unless indicated otherwise in a credit line to the material. If material is not included in the article's Creative Commons licence and your intended use is not permitted by statutory regulation or exceeds the permitted use, you will need to obtain permission directly from the copyright holder. To view a copy of this licence, visit http://creativecommons.org/licenses/by/4.0/.

\section{References}

1. Le Rhun E, Weller M, Brandsma D, VandenBent M, de Azambuja E, Henriksson R, Boulanger T, Peters S, Watts C, Wick W, Wesseling P, Ruda R, Preusser M, Board EE, Committee EG (2017) EANO-ESMO Clinical Practice Guidelines for diagnosis, treatment and follow-up of patients with leptomeningeal metastasis from solid tumours. Ann Oncol 28(suppl_4):iv84-iv99. https:// doi.org/10.1093/annonc/mdx221

2. Lin NU, Gaspar LE, Soffietti R (2017) Breast cancer in the central nervous system: multidisciplinary considerations and management. Am Soc Clin Oncol Educ Book 37:45-56. https://doi. org/10.14694/edbk_175338

3. Morikawa A, Jordan L, Rozner R, Patil S, Boire A, Pentsova E, Seidman AD (2017) Characteristics and outcomes of patients with breast cancer with leptomeningeal metastasis. Clin Breast Cancer 17(1):23-28. https://doi.org/10.1016/j.clbc.2016.07.002

4. Frisk G, Svensson T, Backlund LM, Lidbrink E, Blomqvist P, Smedby KE (2012) Incidence and time trends of brain metastases admissions among breast cancer patients in Sweden. Br J Cancer 106(11):1850-1853. https://doi.org/10.1038/bjc.2012.163

5. Wang N, Bertalan MS, Brastianos PK (2018) Leptomeningeal metastasis from systemic cancer: review and update on management. Cancer 124(1):21-35. https://doi.org/10.1002/cncr.30911

6. Lee YC, Hsieh CC, Chuang JP, Li CY (2017) The necessity of intrathecal chemotherapy for the treatment of breast cancer patients with leptomeningeal metastasis: a systematic review and pooled analysis. Curr Probl Cancer 41(5):355-370. https://doi. org/10.1016/j.currproblcancer.2017.07.001

7. Abouharb S, Ensor J, Loghin ME, Katz R, Moulder SL, Esteva FJ, Smith B, Valero V, Hortobagyi GN, Melhem-Bertrandt A (2014) Leptomeningeal disease and breast cancer: the importance of tumor subtype. Breast Cancer Res Treat 146(3):477-486. https:// doi.org/10.1007/s10549-014-3054-Z

8. Beauchesne P (2010) Intrathecal chemotherapy for treatment of leptomeningeal dissemination of metastatic tumours. Lancet Oncol 11(9):871-879. https://doi.org/10.1016/s1470 $-2045(10) 70034-6$

9. Boogerd W, van den Bent MJ, Koehler PJ, Heimans JJ, van der Sande JJ, Aaronson NK, Hart AA, Benraadt J, Vecht ChJ (2004) The relevance of intraventricular chemotherapy for leptomeningeal metastasis in breast cancer: a randomised study. Eur J Cancer 40(18):2726-2733. https://doi.org/10.1016/j.ejca.2004.08.012

10. Bousquet G, Darrouzain F, de Bazelaire C, Ternant D, Barranger E, Winterman S, Madelaine-Chambin I, Thiebaut JB, Polivka M, Paintaud G, Culine S, Janin A (2016) Intrathecal trastuzumab 
halts progression of CNS metastases in breast cancer. J Clin Oncol 34(16):e151-155. https://doi.org/10.1200/jco.2012.44.8894

11. Rudnicka H, Niwinska A, Murawska M (2007) Breast cancer leptomeningeal metastasis - the role of multimodality treatment. J Neuro-oncol 84(1):57-62. https://doi.org/10.1007/s1106 0-007-9340-4

12. Segura PP, Gil M, Balana C, Chacon I, Langa JM, Martin M, Bruna J (2012) Phase II trial of temozolomide for leptomeningeal metastases in patients with solid tumors. J Neuro-oncol 109(1):137-142. https://doi.org/10.1007/s11060-012-0879-3

13. Lu YS, Chen TW, Lin CH, Yeh DC, Tseng LM, Wu PF, Rau KM, Chen BB, Chao TC, Huang SM, Huang CS, Shih TT, Cheng AL, Taiwan Breast Cancer C (2015) Bevacizumab preconditioning followed by Etoposide and Cisplatin is highly effective in treating brain metastases of breast cancer progressing from wholebrain radiotherapy. Clin Cancer Res 21(8):1851-1858. https://doi. org/10.1158/1078-0432.CCR-14-2075

14. Chen IC, Lin CH, Jan IS, Cheng AL, Lu YS (2016) Bevacizumab might potentiate the chemotherapeutic effect in breast cancer patients with leptomeningeal carcinomatosis. J Formos Med Assoc 115(4):243-248. https://doi.org/10.1016/j. jfma.2015.03.005

15. Wu PF, Lin $\mathrm{CH}$, Kuo CH, Chen WW, Yeh DC, Liao HW, Huang SM, Cheng AL, Lu YS (2015) A pilot study of bevacizumab combined with etoposide and cisplatin in breast cancer patients with leptomeningeal carcinomatosis. BMC Cancer 15:299. https://doi. org/10.1186/s12885-015-1290-1

16. Wolff AC, Hammond ME, Hicks DG, Dowsett M, McShane LM, Allison KH, Allred DC, Bartlett JM, Bilous M, Fitzgibbons P, Hanna W, Jenkins RB, Mangu PB, Paik S, Perez EA, Press MF, Spears PA, Vance GH, Viale G, Hayes DF (2013) Recommendations for human epidermal growth factor receptor 2 testing in breast cancer: American Society of Clinical Oncology/ College of American Pathologists clinical practice guideline update. J Clin Oncol 31(31):3997-4013. https://doi.org/10.1200/ jco.2013.50.9984

17. Lee TH, Avraham H, Lee SH, Avraham S (2002) Vascular endothelial growth factor modulates neutrophil transendothelial migration via up-regulation of interleukin-8 in human brain microvascular endothelial cells. J Biol Chem 277(12):1044510451. https://doi.org/10.1074/jbc.M107348200

18. Herrlinger U, Wiendl H, Renninger M, Forschler H, Dichgans J, Weller M (2004) Vascular endothelial growth factor (VEGF) in leptomeningeal metastasis: diagnostic and prognostic value. Br J Cancer 91(2):219-224. https://doi.org/10.1038/sj.bjc.6601953

19. Carmeliet P, Jain RK (2011) Principles and mechanisms of vessel normalization for cancer and other angiogenic diseases. Nat Rev Drug Discov 10(6):417-427. https://doi.org/10.1038/nrd3455

20. Batchelor TT, Sorensen AG, di Tomaso E, Zhang WT, Duda DG, Cohen KS, Kozak KR, Cahill DP, Chen PJ, Zhu M, Ancukiewicz M, Mrugala MM, Plotkin S, Drappatz J, Louis DN, Ivy P, Scadden DT, Benner T, Loeffler JS, Wen PY, Jain RK (2007) AZD2171, a pan-VEGF receptor tyrosine kinase inhibitor, normalizes tumor vasculature and alleviates edema in glioblastoma patients. Cancer Cell 11(1):83-95. https://doi.org/10.1016/j.ccr.2006.11.021

21. Chen BB, Lu YS, Lin CH, Chen WW, Wu PF, Hsu CY, Yu CW, Wei SY, Cheng AL, Shih TT (2016) A pilot study to determine the timing and effect of bevacizumab on vascular normalization of metastatic brain tumors in breast cancer. BMC Cancer 16:466. https://doi.org/10.1186/s12885-016-2494-8

22. Chen BB, Lu YS, Yu CW, Lin CH, Chen TW, Wei SY, Cheng AL, Shih TT (2018) Imaging biomarkers from multiparametric magnetic resonance imaging are associated with survival outcomes in patients with brain metastases from breast cancer. Eur Radiol 28(11):4860-4870. https://doi.org/10.1007/s00330-018-5448-5

23. Bonneau C, Paintaud G, Tredan O, Dubot C, Desvignes C, Dieras V, Taillibert S, Tresca P, Turbiez I, Li J, Passot C, Mefti F, Mouret-Fourme E, Le Rhun E, Gutierrez M (2018) Phase I feasibility study for intrathecal administration of trastuzumab in patients with HER2 positive breast carcinomatous meningitis. Eur J Cancer 95:75-84. https://doi.org/10.1016/j.ejca.2018.02.032

24. Hu ZI, McArthur HL, Ho AY (2017) The abscopal effect of radiation therapy: what is it and how can we use it in breast cancer? Curr Breast Cancer Rep 9(1):45-51. https://doi.org/10.1007/s1260 9-017-0234-y

25. Boire A, Zou Y, Shieh J, Macalinao DG, Pentsova E, Massagué J (2017) Complement component 3 adapts the cerebrospinal fluid for leptomeningeal metastasis. Cell 168(6):1101-1113.e1113. https://doi.org/10.1016/j.cell.2017.02.025

Publisher's Note Springer Nature remains neutral with regard to jurisdictional claims in published maps and institutional affiliations. 